
Periodica Polytechnica
Civil Engineering

61(2), pp. 196-208, 2017

https://doi.org/10.3311/PPci.9469

Creative Commons Attribution (i)

RESEARCH ARTICLE

\section{Numerical Modeling and Seismic Analysis of Tall Steel Buildings with Braced Frame Systems}

\author{
Vittoria Mazzotta ${ }^{1}$, Emanuele Brunesi ${ }^{2}$, Roberto Nascimbene ${ }^{2 *}$
}

Received 12 May 2016; Revised 14 July 2016; Accepted 27 July 2016

\begin{abstract}
The following paper presents the design and verification steps of tall steel frame structures with braced core, belt and outrigger trusses. The two case study structures refer to sky scrapers of $180 \mathrm{~m}$ and $300 \mathrm{~m}$ respectively, located in Istanbul, Turkey. The main objectives of this study are two: firstly designing the buildings through multilevel structural analysis, secondly to compare the results, in terms of seismic response, between response spectrum analysis (RSA) and nonlinear time history analysis (NLTHA). Such comparison has been made with the intention of investigating the relationship between the structure height and the accuracy of RSA predictions, considering that the latter approach tends to underestimate the influence of higher mode effects. In conclusion the capacity curves of the two structures, developed using incremental nonlinear dynamic analysis, are presented as an ulterior way to assess the seismic capacity of such type of high-rise structural systems.
\end{abstract}

\section{Keywords}

tall steel buildings, concentrically braced frames, response spectrum analysis, nonlinear dynamic analysis

${ }^{1}$ ROSE Programme, UME School, IUSS Pavia, Institute for Advanced Study, 27100 Pavia, via Ferrata 1, Italy

${ }^{2}$ EUCENTRE, European Centre for Training and Research in Earthquake Engineering, I-27100 Pavia, via Ferrata 1, Italy

*Corresponding author, e-mail: roberto.nascimbene@eucentre.it

\section{Introduction}

The design of a tall building, characterized by definition by its significant slenderness and a long vibration period [1-8] must pay particular attention not only to vertical loads, but also to the horizontal ones, such as wind and earthquakes, which require greater control of displacement and structural strength, since they may induce significant oscillations and effects of the second order are no longer negligible. The structural systems designed to withstand these actions, are the bracing structures which by their nature, affect the choice of the entire structural scheme. It should be highlighted that, since this paper focuses on buildings that are $180 \mathrm{~m}$ tall, at least, to calculate the wind action, it was not possible to refer to European codes, because they do not specify how to study the effects of such an action when building is taller than $100 \mathrm{~m}$. Therefore, it was necessary to refer to American guidelines and standards $[9,10]$ that were assumed as an alternative approach, as shown in the following sections. Instead, the effect of the seismic action was assessed comparing two models: the first one is based on a linear elastic constitutive approach and subjected to modal dynamic analysis with a design spectrum, carried out through SAP2000 software [11]; the second one, having more sophisticated constitutive laws, was developed adopting a distributed plasticity approach and then subjected to a series of nonlinear dynamic analyses, carried out within the open platform OpenSees [12]. Although high-fidelity finite element (FE) models commonly used for seismic analysis and/or topology optimization of steel and reinforced concrete structural systems and components [13-21] are able to reproduce local stress/strain concentrations, the computational effort increases tremendously. Therefore, such an approach is currently unfeasible for design office use, especially whether the response of entire super-tall mega-frame buildings with their key structural components has to be assessed in a nonlinear dynamic fashion. In light of this, mechanical idealizations and fiber-based representations were proven to be a promising and viable approach when used to predict the nonlinear behavior of such systems at a global level, as shown by several comparisons against experimental tests [22-27]. 
The need for simplified inelastic beam-based techniques to be integrated in a framework for large scale nonlinear dynamic analysis was indeed based on the awareness that a linear modal analysis cannot adequately assess the contribution to seismic response from higher vibration modes, which in this specific case represent a significant source of additional stresses in tall and super-tall building prototypes. It is clear that the internal forces (i.e. shear, moment and axial force) that develop during seismic excitation are highly affected by a prevailing elastic response along higher modes of vibration, and that a modal dynamic analysis with a constant behavior factor $(q)$ for all vibration modes cannot properly interpret the phenomenon just described. Thus, the work reported in this paper is devoted to describe the basis of structural design, aforementioned analyses and the comparison of obtained results, paying particular attention to some of the key elements of the two steel megaframe systems under investigation. Lastly, several nonlinear dynamic analyses were carried out to investigate the dynamic behavior at different levels of seismic intensity.

\section{Case-study structures}

The two frames, object of study, respectively of 45 and 75 stories are characterized by the joint combination of an inner braced ring and inner trusses capable to withstand horizontal loads. Both structures are characterized by an interstory height of $4 \mathrm{~m}$, with a total height of $180 \mathrm{~m}$ and $300 \mathrm{~m}$ respectively and 6 spans of $8 \mathrm{~m}$ each. Hereinafter the two structures were identified as frame A (45 stories) and frame B (75 stories).

\subsection{Geometrical characteristics}

The chosen structural system, as already mentioned in the introduction, combines a central braced element arranged with an outriggers system (or belt trusses), which is an interior reticular girder system that connect the central core with the exterior columns. In this manner, the structure subjected to horizontal actions benefits from a stiffening contribution offered by the upwind columns which are under tension, thus enabling the achievement of high interstory heights. It should be highlighted that the choice of a structural system such as the one mentioned above is highly dependent on the number of stories of the building and on the type of material used for the construction, which in fact affect the magnitude, the effects of horizontal loads and consequently the most suitable structural scheme to withstand them. Furthermore, also the positioning of the internal reticular girders (trusses), whose purpose is to reduce as much as possible the interstory drift value, was subjected to extensive studies which demonstrated that the optimum choice for their positioning is once again linked to the number of stories. The outcome of the study $[28,29]$ led to the decision for the final configuration of both buildings. More specifically, the outriggers were positioned at a constant interval of fifteen stories.

The braces were $\mathrm{V}$ arranged, in other words a concentrically braced frame (CBF) system was considered (see Fig. 1). Since the final goal was to obtain a brace cruciform configuration, the brace direction was reversed from a story to another one, thus creating a cross every two stories. Therefore, this choice allowed solving the flexural force problem (caused by the unbalanced tensile force of the brace under tension) in the girder where the diagonal elements converged, since the force was absorbed by the brace placed on the upper story. The girder-column joint was designed by using four gusset plates welded to the column flange and bolted to the web and flange of the girder. For the girder-column-brace connection, a gusset plate was used that in turn was welded to the brace using four fillet welds, while to join it to the girder-column connection a whole penetration welding was used. It should be noted that IPE profiles were used for the girders, HD profiles were used for the section of columns and interior trusses, and hot-formed square hollow profiles were used for the braces. Furthermore, the structural members were designed by using a class S275 steel for the IPE section and a class S450 steel for the HD sections.

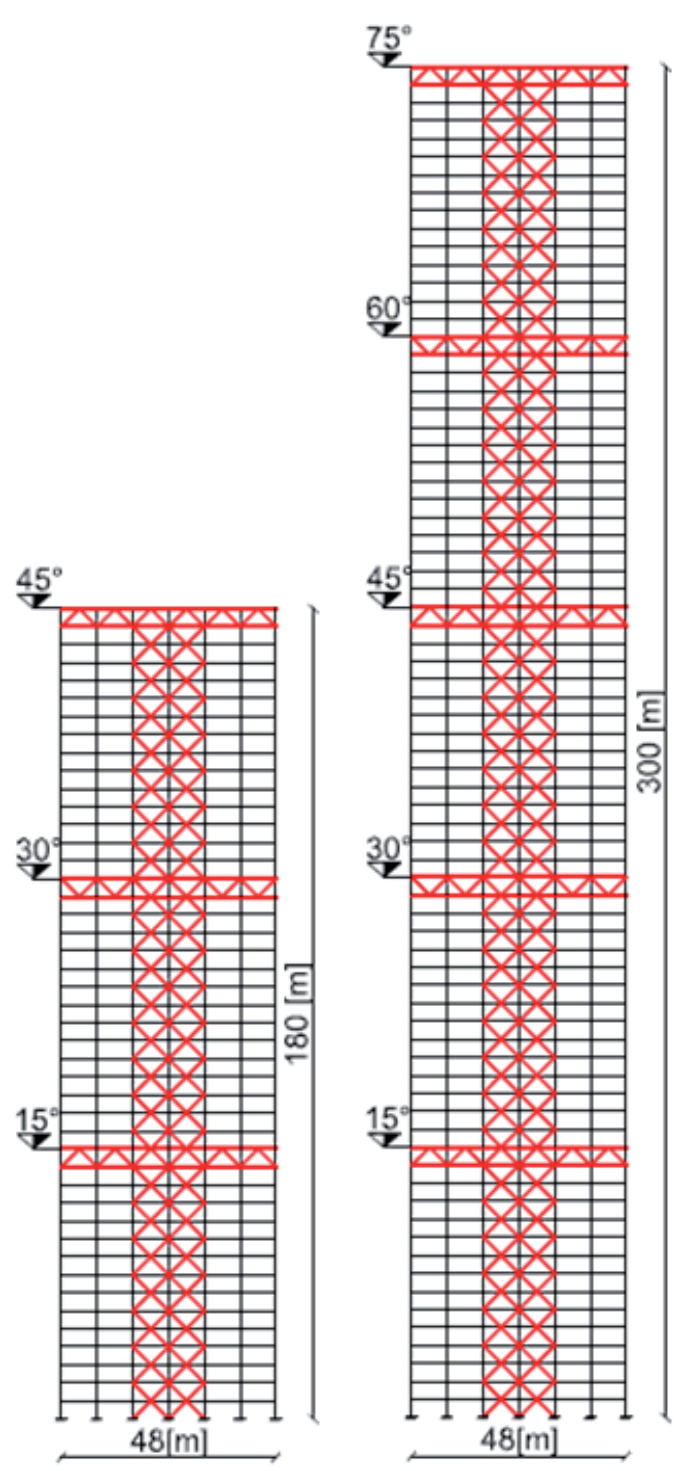

Fig. 1 Frame with braced core, belt and outrigger trusses. 


\subsection{Load definition and design assumptions}

The construction site was near the city of Istanbul in Turkey. The first design of the two frames required an analysis of both vertical and horizontal loads, due to wind and earthquake. More specifically, regarding the horizontal loads, a square meter load acting over the vertical surfaces of the building was considered, both for wind action and for the seismic action, the latter calculated through an equivalent linear static analysis. The comparison of internal forces, induced by the external loads, through this analysis procedure highlighted that the wind effects are negligible compared to the effects of seismic action.

\subsubsection{Wind Action}

For the calculation of the horizontal load due to the wind, as mentioned in the introduction, it was necessary to use the analytical procedure described by American codes $[9,10]$. In so doing, it was possible to take into account the load amplification due to the wind gusts, which may cause structural resonance. The approach used to calculate the pressure $p_{z}$, is shown below:

$$
p_{Z}=q_{Z} \times G R F \times C_{P}
$$

It specifies that the pressure is proportional respectively to the pressure $\mathrm{q}_{\mathrm{z}}$ linked to the speed in psf at a height of $z$ above the road level, to the dimensionless coefficient GRF (Dynamic Response Factor), which amplifies the average load to include the effects of random gusts and fluctuating forces induced by structure displacements through the wind, and finally it is also proportional an external pressure coefficient $\left(C_{p}\right)$. This coefficient is variable with the height of the building and acts as pressure on the windward surface and as depression on the leeward surface on the roof.

For the sake of brevity, the procedure used to calculate the parameters that contribute to define the pressure is not reported here in full. The next paragraphs show the diagrams related to total pressure, considering linear sum of upwind and leeward contributions, both for frame A and for frame B. In the calculation of the horizontal load due to wind pressure, which was carried out according to ASCE-7 05 provisions [10], a basic wind speed equal to $37 \mathrm{~m} / \mathrm{s}(84 \mathrm{mph})$ has been assumed for both structures.

\subsubsection{Seismic input}

The calculation of earthquake action and its effects through an equivalent linear static analysis [30], first of all required the identification of the design spectrum, defined according to [30] and following the choices shown below:

- Type of spectrum: 1;

- Type of soil: C;

- Peak acceleration ag: $0.4 \mathrm{~g}$;

- $\mathrm{T}_{\mathrm{D}}$ equal to $8 \mathrm{~s}$;

- Viscous damping: 5\%;

- Behavior factor q: 2
In addition, the different vertical loads acting on the two structure were assumed to be equal to:

- DL: $2 \mathrm{kN} / \mathrm{m}^{2}$;

- LL: $4 \mathrm{kN} / \mathrm{m}^{2}$

Where DL and LL are dead and live loads, respectively. By applying the procedure shown in the Eurocode [30], regarding the equivalent linear static analysis, it was possible to analyze preliminarily the action induced by the earthquake to all the story levels of the two structures. With the intention of assessing the predominant action between seismic action and wind action to be used during the preliminary sizing, the concentrated forces arising from the earthquake were transformed into normalized pressure per square meter.

The following figures (Figs. 2 and 3) show graphically the comparisons between the two horizontal actions.

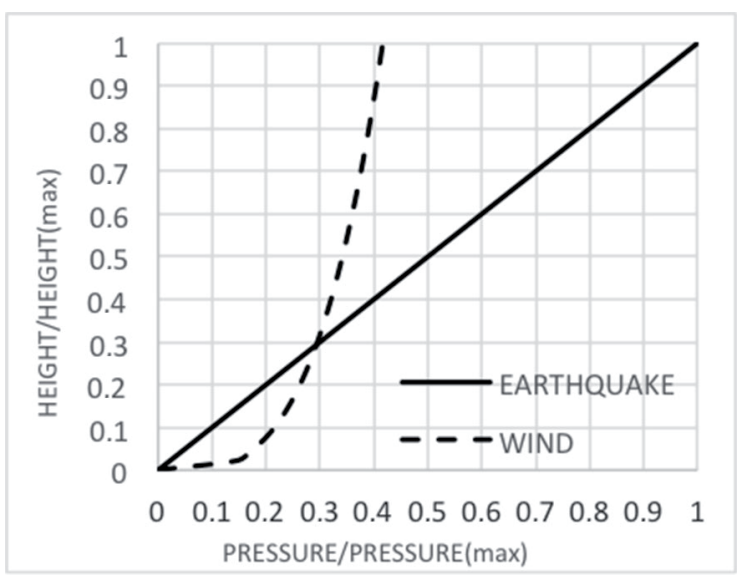

Fig. 2 Comparison between actions - FRAME A.

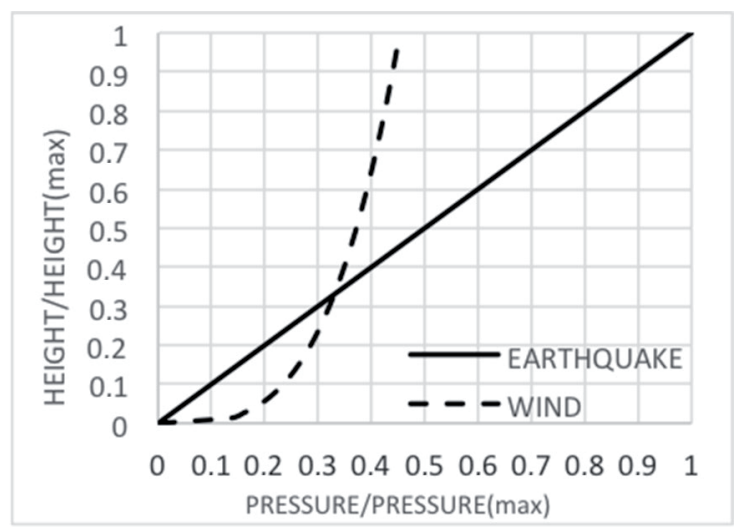

Fig. 3 Comparison between actions - FRAME B.

Although low-frequency vortex shedding and aerodynamic characterization may have in some cases a significant impact on the response of tall buildings (see e.g. Petrini and Ciampoli [31]), such a comparison, carried out in terms of imposed loads at this stage, revealed the earthquake excitation to be the most demanding of the two conditions. As such, wind and seismic loadings were considered in parallel during the design phase of the two case-study structures, as discussed later on, and then detailed building assessment was performed paying deeper and 
particular attention to earthquake-induced demand. A similar approach was assumed in other research studies (see e.g. [6-8, 32]). Accordingly advanced seismic analyses were presented and discussed in the following in order to assess the buildings under consideration, thus quantifying how sensitive they are to dynamic effects and multi-mode response.

\subsubsection{Preliminary design}

It is worth noting the different approach with which the various structural elements were designed. More specifically, the braced core, where it is assumed that almost the totality of horizontal actions is concentrated, was sized starting from the preliminary seismic action calculated from the equivalent linear static analysis. Regarding the other elements (girders and columns) of structures under testing, the geometries were defined only based on vertical loads [30].

It should be highlighted that at the time of structural design, more particularly regarding the bracing system, it was assumed that both the braces under tension and the compressed ones would contribute to withstand the seismic action. However, in the modeling stage, to take into account that once the instability of the critical load was reached the compressed braces would become negligible in terms of strength and stiffness, only the contribution of the diagonal element compressed up to $30 \%$ of the load which caused the instability was taken into account [25]. Finally, during the sizing of the structure, the girder-tocolumn connections were sized in such a way to remain within the elastic range in accordance with the instruction specified in the Eurocode 3 [33], while the gusset plates that connected the diagonal elements to the girders and columns of the frame were sized according to the detailed rules referred to in [9], considering a band that was $2 \mathrm{t}$ wide (where $\mathrm{t}$ is the plate thickness), calculated from the end of the diagonal element. It is expected that the latter would be the location where the plastic hinges would form. The following tables (Tables 1 and 2) show the class 1 sections used for structural frameworks. As previously mentioned in the previous Section, earthquake excitation governed the design process of both tall buildings as it represented the most severe loading condition.

Table 1 Brace sections - Frame A and Frame B.

\begin{tabular}{lc}
\hline & FRAME A \\
\hline Floors & Braces \\
From 1 to $5,15,30$ & HSS $300 \times 300$ \\
From 6 to 29,45 & HSS $250 \times 250$ \\
From 31 to 44 & HSS $180 \times 180$ \\
\hline & FRAME B \\
\hline Floors & Braces \\
From 1 to 20 & HSS $400 \times 400$ \\
From 21 to 55 & HSS $350 \times 350$ \\
From 56 to 75 & HSS $300 \times 300$ \\
\hline
\end{tabular}

Table 2 Column sections - Frame A and Frame B.

\begin{tabular}{lc}
\hline & FRAME A \\
\hline Floors & Braces \\
From 1 to 10 & HD $400 \times 900$ \\
From 11 to 20 & HD $400 \times 509$ \\
From 21 to 30 & HD $400 \times 314$ \\
From 31 to 45 & HD $400 \times 187$ \\
\hline & FRAME B \\
\hline Floors & Braces \\
From 1 to 25 & HD $400 \times 1299$ \\
From 26 to 38 & HD $400 \times 900$ \\
From 39 to 54 & HD $400 \times 634$ \\
From 55 to 65 & HD $400 \times 509$ \\
From 66 to 75 & HD $400 \times 314$ \\
\hline
\end{tabular}

IPE500 sections were used for girders on the various stories, while HD 400×314 sections were used for the upper and lower stringers of the outriggers. High-strength steel was used for braces according to [34].

\section{Structural response}

As mentioned in the introduction, to assess the structural response as well as to design and verify the structural frameworks, given the specific difficulties related to the assessment of the structural behavior of very tall buildings, different finite element models were developed. The purpose of this choice was to develop different types of analysis on the structures under examination in order to avoid the risk of underestimating the effects of the higher vibration modes that would happen if the sole use of modal dynamic analyses with design spectrum were used.

Consequently, three types of analysis were carried out:

- linear response spectrum analysis (RSA);

- nonlinear time history analysis (NLTHA);

- nonlinear incremental dynamic analysis (IDA).

As widely explained in the introduction, the first two types of analysis were carried out with the aim of assessing the inaccuracy of RSA, which in turn affects the effectiveness of current European seismic rules when they are applied to this type of flexible mega-braced frame-core buildings. In light of this, global structural performance and local response of key members were investigated comparing the response obtained using analysis methods with different levels of sophistication. Finally, the third type of analysis was carried out with the aim of collecting more exhaustive understanding on the structural response of those buildings, thus quantifying any additional strength/ductility reserve that they may possess. More than 200 dynamic nonlinear analyses were performed to construct the dynamic capacity curves for the two case-study frames under examination. 


\subsection{Multimodal dynamic analysis}

More specifically, the first model developed for carrying out the dynamic modal analysis was performed using the SAP2000 calculation code [11]. This model is characterized primarily by the assumption of a linear elastic constitutive model for the materials. On the other hand, regarding the constraint conditions, it was presumed that perfectly fixed joints were present at the base of the two frames; the upwind-girder-column connections were considered as infinitely stiff. Finally, in order to schematize the behavior of the girder-column joints for which hypothesis of infinite stiff was deemed unlikely because no diagonal elements were present, springs with rotational stiffness were included and sized on the basis of simplified diagrams, with the purpose to schematize the interaction in terms of stiffness between the two elements at the joint.

After having implemented the vertical and horizontal wind loads referred to in section 2.2 and combined them according to [30], a first eigenvalue analysis was carried out, from which it was possible to obtain modal information related to the two frames. Specifically, for frame A it was possible to obtain a first period corresponding to $4.8 \mathrm{~s}$, while the first mode of vibration corresponded to $8.3 \mathrm{~s}$ in case of frame B. For both configurations, it was found that the participating mass ratio was approximately $65 \%$, and it was also possible to reach $85 \%$ of the total mass, for both frames, only with the $3^{\text {rd }}$ mode of vibration. After that, a modal dynamic analysis with the design spectrum was carried out, assuming that a unique behavior factor was considered for all modes of vibration. The CQC combination rule was assumed for modal superposition of the effects of the earthquake excitation.

After having defined the internal forces in the structural elements, the first verifications of the structural framework sections were carried out according to what is specified in $[30,33$, 34], subsequently they were compared to those obtained on the basis of nonlinear dynamic analyses.

\subsection{Nonlinear dynamic analysis}

Concerning the nonlinear dynamic analysis, the modeling of the two frames was carried out using the calculation program OpenSees [12] and in particular, a series of FE models were developed to carry out nonlinear analyses. For these analysis, braced elements, girders and columns were assigned a Menegotto-Pinto constitutive model through a distributed plasticity model using a classical force-based formulation [33-35]. The girder-column joints were assigned a spring element, which was provided with a linear elastic constitutive model for rotational and translational degrees of freedom out of the plane, and an elastic constitutive model perfectly plastic for the rotation on the plane. Finally, the areas where the brace gusset plates act, were modeled as a linear elastic elements. The large displacement nonlinear analyses were carried out by subjecting the structure to a seismic input which was represented by a set of ten natural accelerograms [36]. They were assumed to be code-compliant displacement spectrum-compatible records in accordance with the criteria specified in section 2.2.2. Fig. 4 shows the comparison between the average response spectrum obtained from the suite of ground motions assumed herein to perform NLTHAs and the EC8-compliant design spectrum that was considered for RSA.

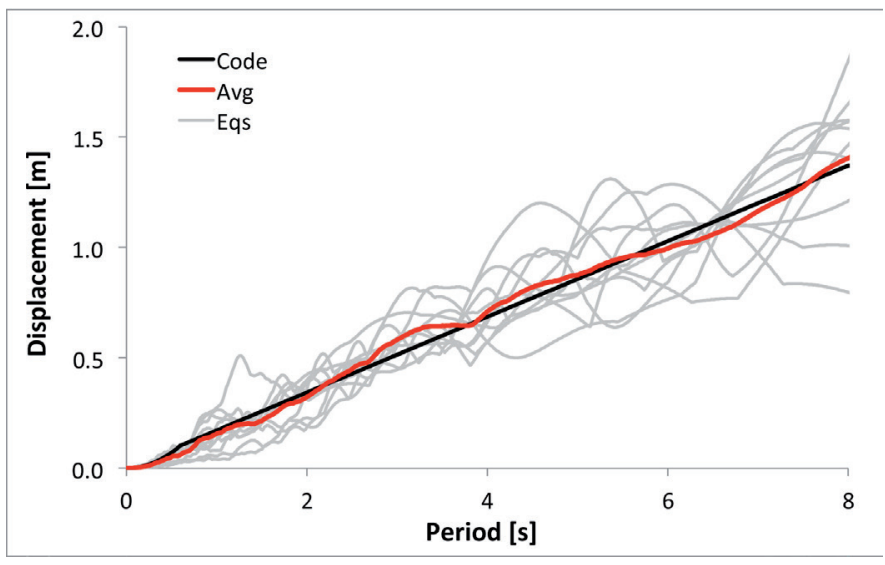

Fig. 4 Spectral compatibility according to European rules [30].

Although no unanimous consensus has been yet achieved on a unique procedure for selection of seismic input, the approach assumed to obtain a compatible set of records plays a key role in seismic analysis and earthquake-resistant design. Several contributions [39-43] constitute the theoretical background for the scaling process carried out in order to determine reliable numerical estimates with an acceptable level of confidence. These studies have shown that ground motion records can be multiplied by a constant scale factor (SF) with bounded values (i.e. less than 10) without affecting substantially the results of nonlinear dynamic analyses using these records. The EC8 [30] permits the time history representation of the ground motion in terms of natural ground motions, artificial accelerograms and simulated records. More in detail, simulated accelerograms are usually employed to a lesser extent in the engineering practice if compared with real and artificial records, because they require a comprehensive knowledge of the seismotectonic setting of the area under study and a large number of input parameters concerning earth crust rupture and travel path mechanisms. In addition, the ground motion characteristics of artificial accelerograms (e.g., frequency content, duration, phase correlation, etc.) are strongly dependent on the adopted generation algorithm and they can be very different from those of real time series. By contrast, accelerograms recorded during real earthquakes are preferable, since they possess a realistic lowfrequency content, as recognized in EC8 [30]. Therefore, ten (in lieu of seven) natural ground motions were selected from PEER NGA database and they were scaled to obtain spectrum compatibility in average, considering a medium-to-large period range, which is in agreement with the dynamic characteristics 
of the two case-study structures. Those ten records were all recorded on sites conforming to EC8 soil type $\mathrm{C}$ and originate from earthquakes ranging in magnitude from 6.2 to 7.6. The procedure assumed in this research for selecting them takes advantage of SF less than 6 and does not introduce any frequency context adjustment using wavelet in order to match the target design spectrum. Furthermore, the choice of a corner period $\left(T_{D}\right)$ equal to $8 \mathrm{~s}$ (instead of $2 \mathrm{~s}$ ) was due to studies (e.g. [42, 43]), in which an exhaustive characterization of long-period ground motion for seismic design of structures was proposed, thus showing that long period values can be expected in Italy and in other parts of the world.

Therefore, NLTHAs were conducted in accordance with the aforementioned criteria and the prevailing numerical results obtained were presented and discussed in the following. Figs. 5 and 6 show the peak interstory drift profiles determined for Frame A and Frame B, respectively.

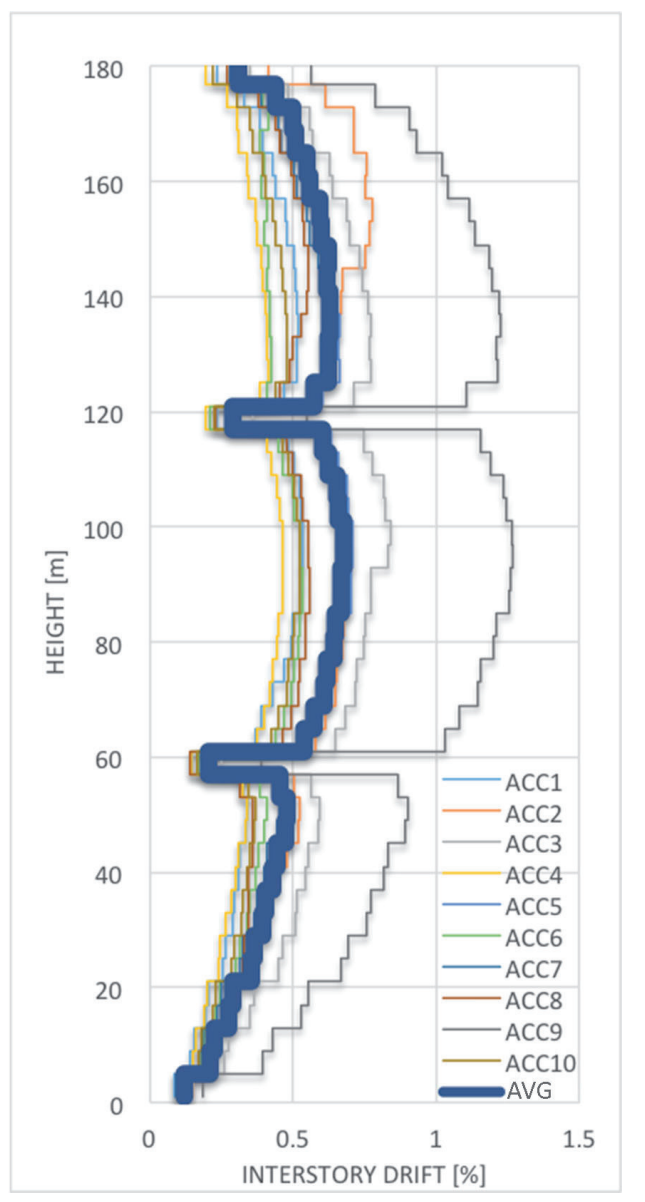

Fig. 5 Interstory drift - Frame A.

Nonlinear dynamic analysis provided horizontal absolute displacements, which once normalized based on story height, allowed obtaining interstory drift profiles. It is important to highlight that by adopting this particular bracing system, whose main objective is to constrain displacements and to limit their structural deformation (Figs. 5 and 6), it is possible to significantly reduce the interstory drift of this type of high-rise structural systems, thus complying with one of main design check for these flexible structures. In fact for both case studies a peak drift value of $0.7 \%$ was obtained.

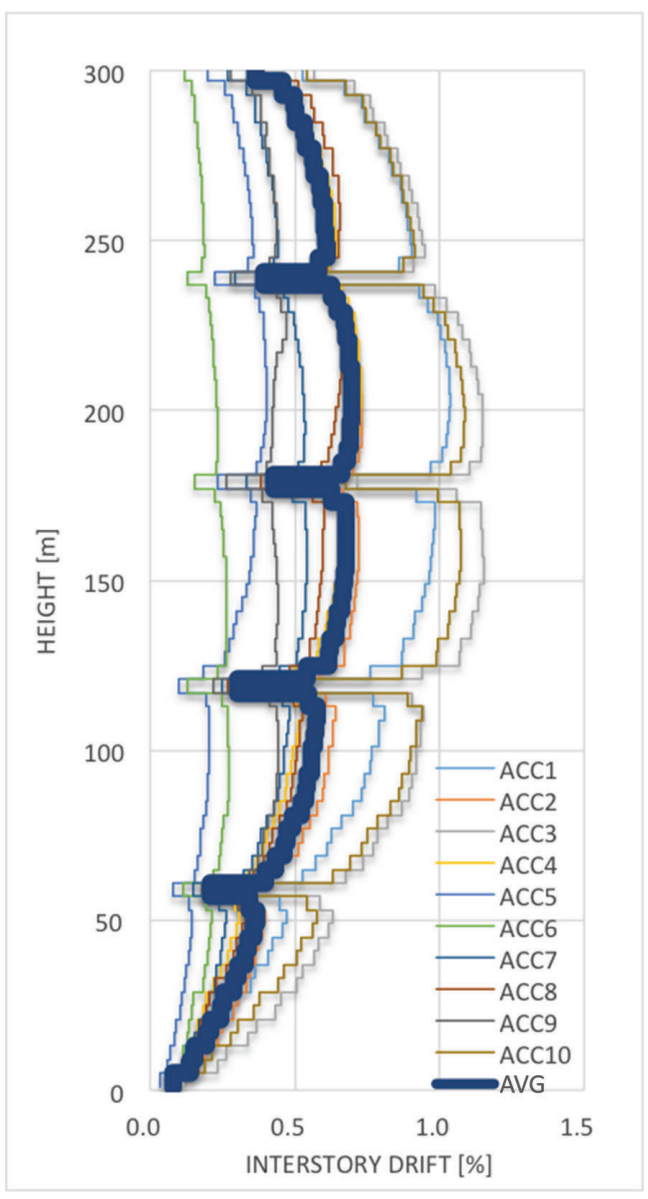

Fig. 6 Interstory drift - Frame B.

Fairly cantilever-like deformed shapes with discontinuities in correspondence to the outriggers were obtained for the two mega-structures, which presented peak roof displacements of about $1.71 \mathrm{~m}$ and $2.56 \mathrm{~m}$ in the case of the most severe record. Peaks of up to $0.91 \mathrm{~m}$ and $1.56 \mathrm{~m}$ were determined in average for frame A and frame B, respectively. Even if outriggers/belt trusses were shown to be effective for stiffening/strengthening, they resulted in a large increase in floor accelerations, which in turn caused concentrations of shear force and bending moment demands to occur in the columns of the structures. A similar effect was also predicted in terms of axial forces acting on the braces of the core, as discussed later on. In detail, the average peaks in terms of story acceleration were $0.38 \mathrm{~g}$ and $0.37 \mathrm{~g}$ in frame A and frame B, respectively. Maxima of up to $0.98 \mathrm{~g}$ and $0.68 \mathrm{~g}$ were experienced by the two prototypes, in case that the most severe ground motion was taken as reference. The higher mode effects were reaffirmed to be significant for this type of structures, and their contribution was particularly pronounced in the upper stories of the tallest mega-braced building, due to its higher flexibility. As such, although the benefits from the contribution of the outriggers are well-known since the sixties, 
the analysis results revealed that particular care has to be paid to these members during the design process, particularly when RSA-based approaches are assumed as permitted in the current version of the European rules.

\subsection{Incremental dynamic analysis}

Incremental dynamic analysis (IDA) approach was intended to investigate the seismic behavior of a structure at different levels of seismic intensity [44]. Using a given accelerogram, different dynamic analyses are carried out with a seismic input arranged in ascending manner up to reaching either structural collapse or a predetermined level of deformation/displacement. By operating in this manner, it was possible to follow the development of the building structural response, depending on the increasing seismic force. By arranging the ten natural accelerograms through ten factors, it was possible to construct point by point the capacity curves of the two prototype frames for each record, as presented in Fig. 7 and 8. In the diagrams of the figures shown below, the abscissa axis shows the value of maximum displacement of a fixed control node at the top of the structure, while the ordinate axis shows the value of the maximum shear force recorded at the base.

The maximum displacement value reached was about $2.6 \mathrm{~m}$ for frame A and about $4.5 \mathrm{~m}$ for frame B. The displacement values were in accordance with the inelastic displacement value which, according to regulations of the Uniform Building Code (UBC) [45] released in 1997 and subsequent ones, was limited to $2 \%$ of the structure height, thus placing in our case a limit of $3.6 \mathrm{~m}$ for Frame A and $6 \mathrm{~m}$ for Frame B. The trend of the capacity curves obtained from different accelerograms were almost perfectly linear, meaning that the two structures remained in the pseudoelastic linear range with a small plastic use, confirming that the nature of concentric braces is almost non-dissipative, when such a design target is assumed [30]. As discussed in the sections concerning the initial design of the two structures, they were indeed designed in medium ductility class in accordance with EC8 [30].

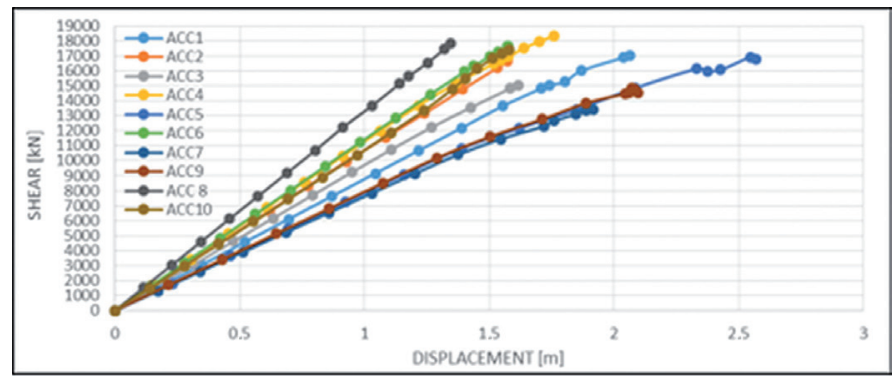

Fig. 7 Capacity curves - Frame A.

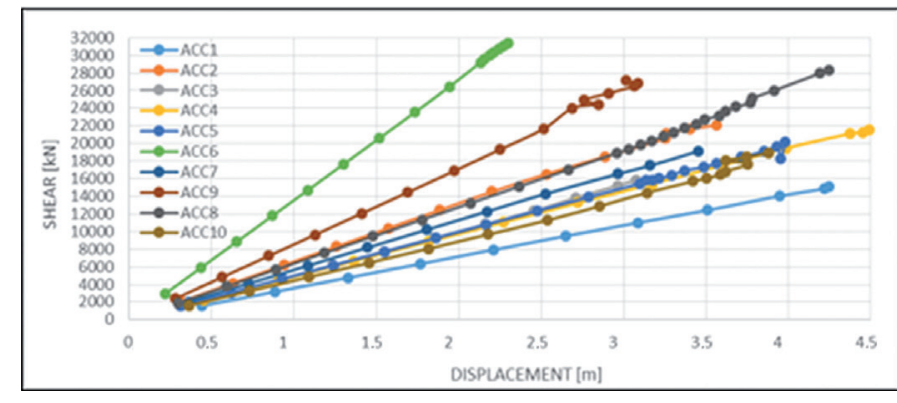

Fig. 8 Capacity curves - Frame B.

\section{Comparisons and observations}

Once the global structural performance of the two reference buildings was investigated, the local response of key members was explored. The effects of outriggers/belt trusses and bracing systems were therefore studied at a local level in this section. Sensitivity to the structure height was quantified by comparing the response of the two case study frame-core structures and a paradigm was developed to relate the behavior observed using different types of analysis. The following comparison may thus serve as a reference for earthquake-resistance design/analysis of super-tall buildings of similar type.

Some crucial structural elements were selected and the set of results obtained using RSA were compared to the average of NLTHAs, in order to identify peculiar trends. First of all, the central and lateral columns of frames A and B were considered and the axial force peak profiles were shown, revealing that the former remained almost unaffected by the in-plane rotation of the outriggers (see Figs. 9 and 10). On the other hand, a more significant influence was observed as far as the lateral column is concerned (Figs. 11 and 12). Such an outcome is obviously not surprising, since central elements are minimally involved in this secondary earthquake-induced mechanism. Accordingly an almost perfect match can be observed in Figs. 9 and 10, if the compressive forces predicted using the two different types of analysis are compared. As shown in Figs. 11 and 12, a large difference was obtained in the lateral columns in terms of axial compressive loads, since these members participate in a more pronounced manner to this resisting mechanism, counteracting the overturning moment induced by an earthquake. 


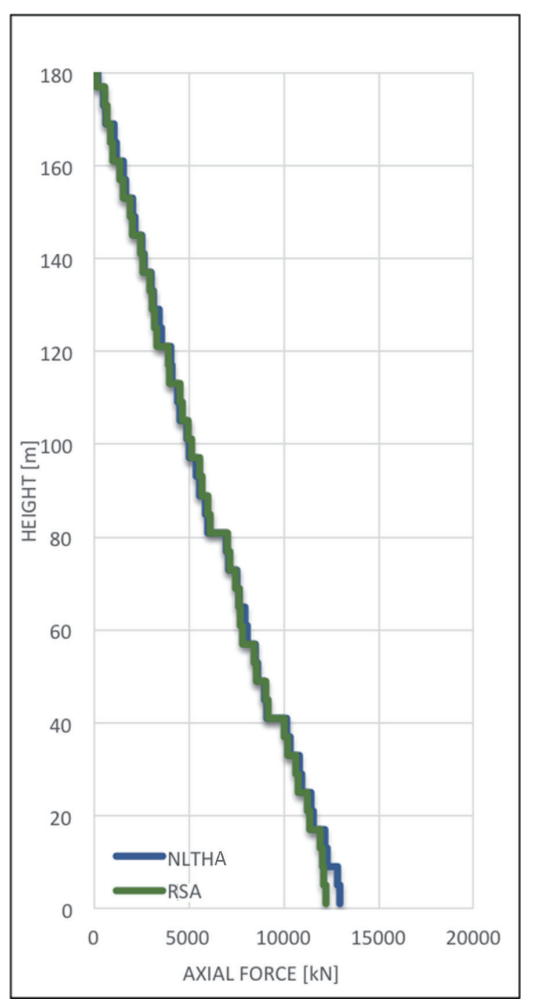

Fig. 9 Compressive axial force - Frame A, central column.

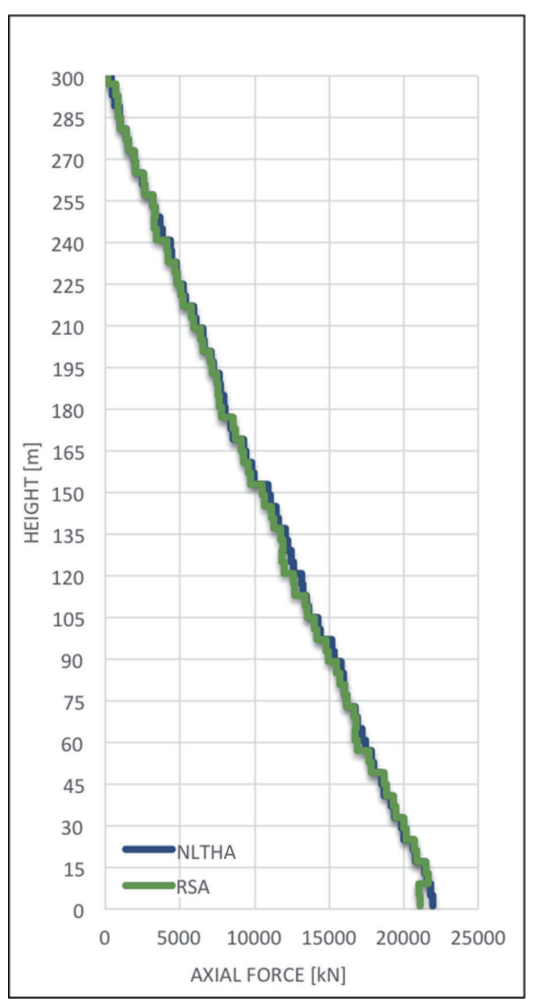

Fig. 10 Compressive axial force - Frame B, central column.

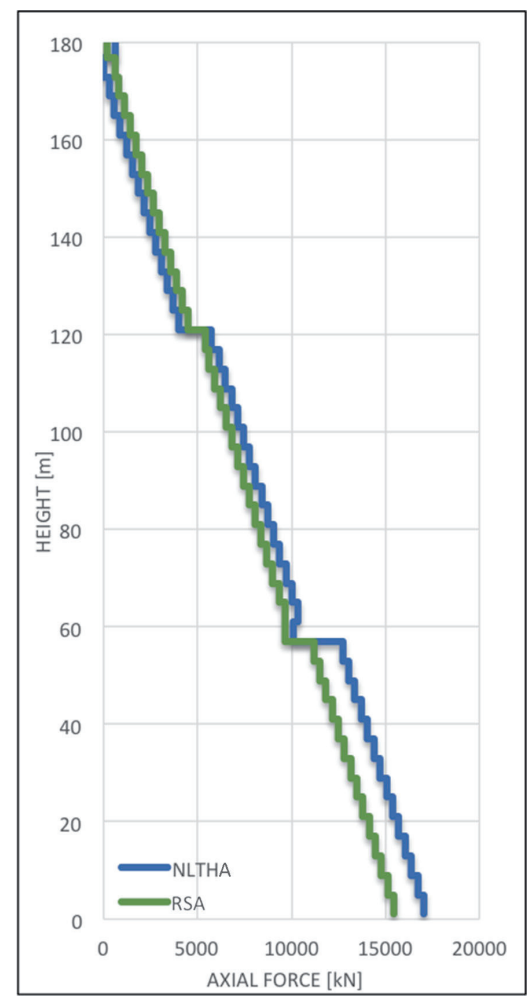

Fig. 11 Compressive axial force - Frame A, lateral column.

It is worth mentioning that these differences tend to increase with the total building height, that is a direct consequence of the significant contribution of the higher modes. NLTHA is in fact able to properly take them into account, while RSA simply superimposes the contribution from different modes, making use of a unique behavior factor to account for any source of nonlinearity. The maximum discrepancy was recorded at the base and was equal to $9 \%$ and $20 \%$ for frames $\mathrm{A}$ and $\mathrm{B}$.

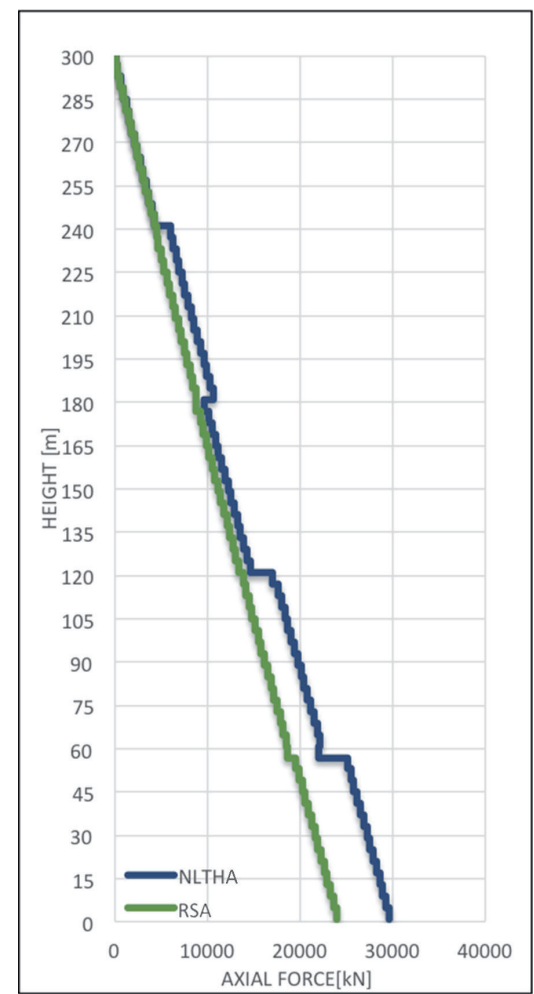

Fig. 12 Compressive axial force - Frame B, lateral column. 
Secondly, the peak compressive axial forces experienced by bracing elements were collected and the results obtained from RSA and the average of NLTHAs were presented considering a representative left and right brace of the core. In particular, Figs. 13 and 14 show the trends observed for Frame A, while those determined in case of Frame B are depicted in Figs. 15 and 16.

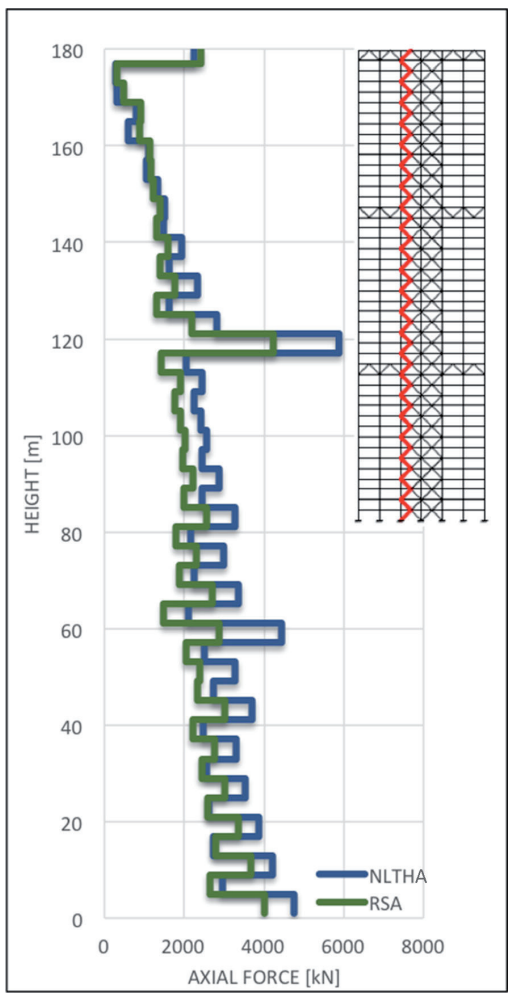

Fig. 13 Compressive axial force - Frame A, left braces.

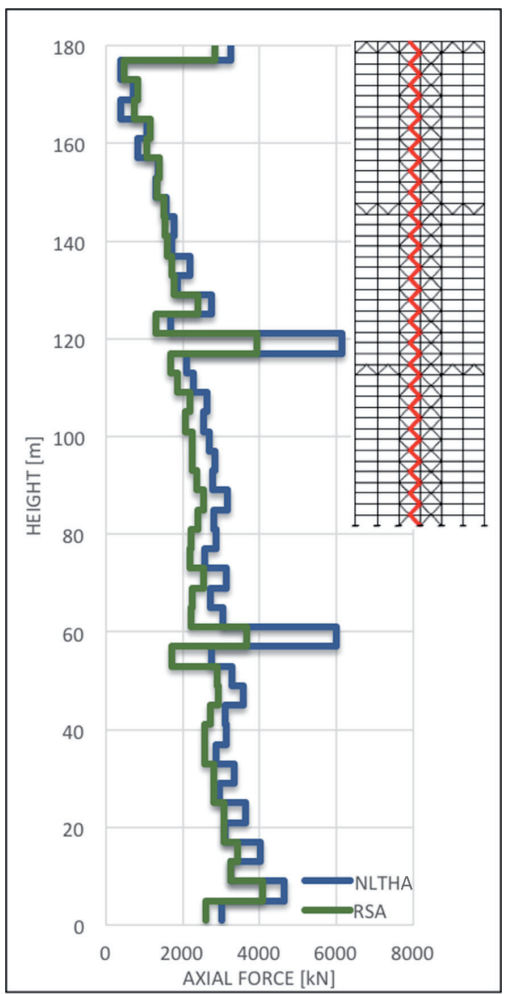

Fig. 14 Compressive axial force - Frame A, right braces.
Also in case that braces are concerned there are significant differences between the two types of analysis. As it can be seen from each of the four plots, the axial force peak profiles revealed a visible mismatch between the estimates of RSA and the predictions obtained considering the average of NLTHAs. This was observed along the entire height of the two buildings and, in addition, peaks were recorded in correspondence to the outriggers. More specifically, the largest difference in terms of compressive force was shown for both frames in the braces at the $15^{\text {th }}$ story. Considering Frame A, those values are equal to $55 \%$ and $64 \%$ for the left and right braces, respectively (Figs. 13 and 14). As far as frame B is concerned, a discrepancy of up to $98 \%$ and $100 \%$ was computed in case that left and right braces are considered.

More in detail, the difference between the axial compressive forces obtained from the two types of analysis were computed and shown systematically for each prototype under study. Figs. 17 and 18 highlight those obtained for the 45-story building, while the discrepancy determined for the 75-story structure are collected in Figs. 19 and 20. A direct comparison between the two case study structures is also shown in Figs. 21 and 22 for both left and right braces. The structural response obtained for both structures reaffirm the importance of using NLTHAs as a post-design check tool, since RSA visibly underestimates axial demands on these key members. The mismatch is particularly evident for the tallest of the two structures, as consequence of a more pronounced contribution from the higher modes (Figs. 21 and 22).

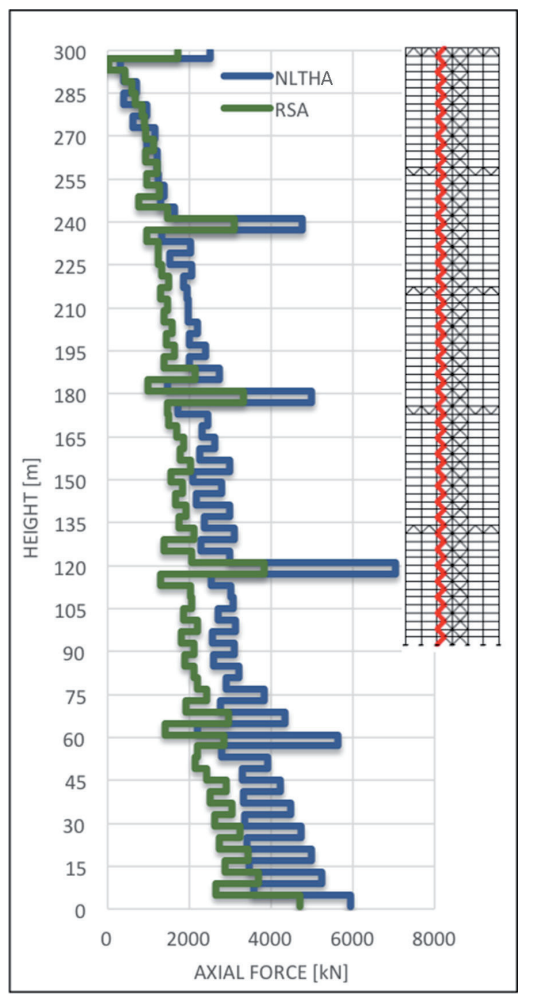

Fig. 15 Compressive axial force - Frame B, left braces. 


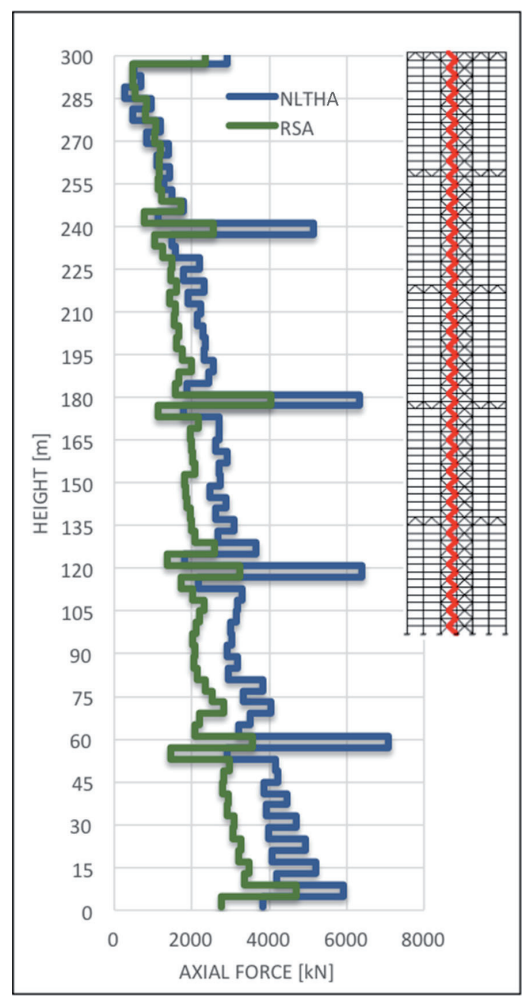

Fig. 16 Compressive axial force - Frame B, right braces.

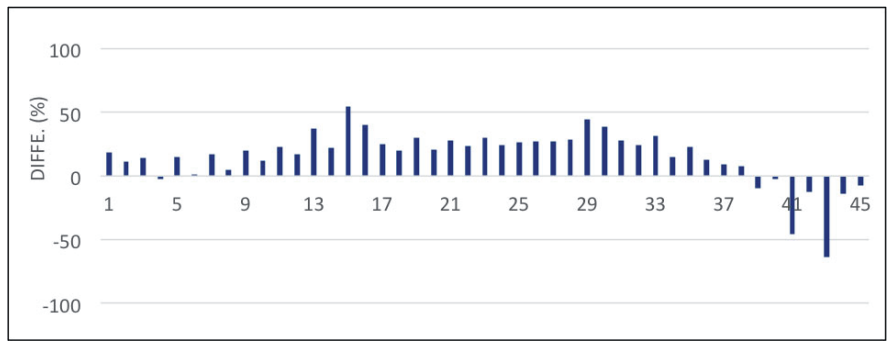

Fig. 17 Frame A, left braces - difference in terms of axial force level.

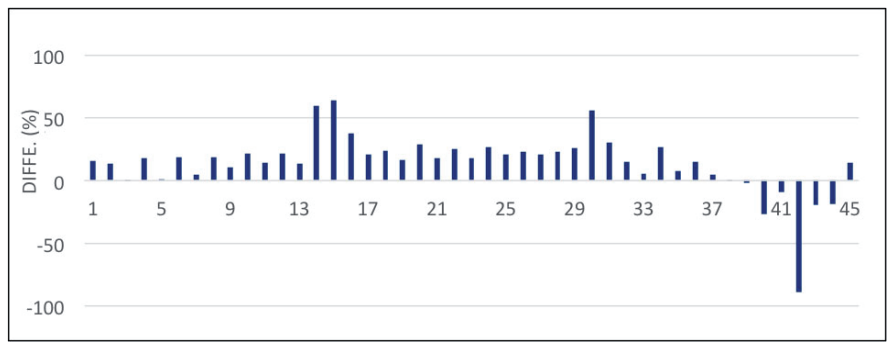

Fig. 18 Frame A, right braces - difference in terms of axial force level.

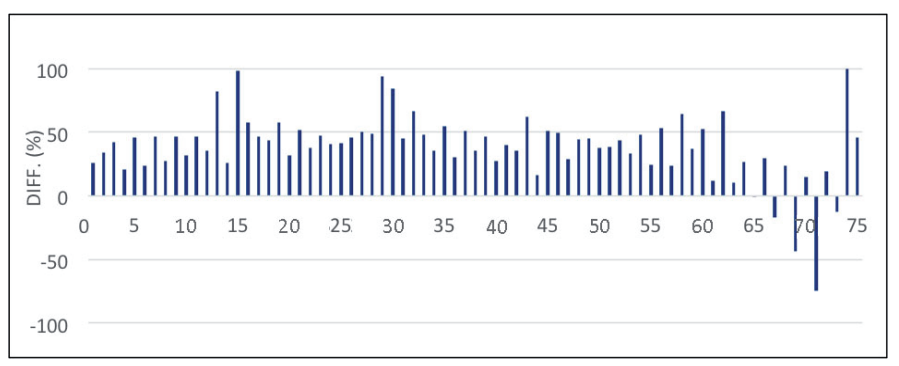

Fig. 19 Frame B, left braces - difference in terms of axial force level.

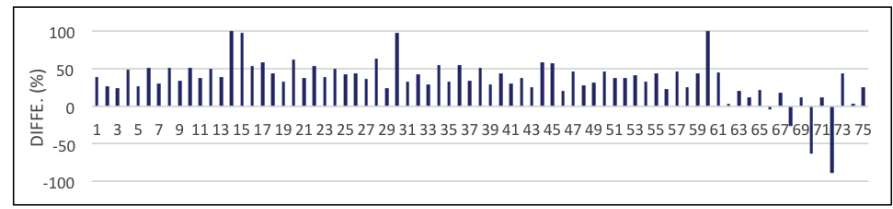

Fig. 20 Frame B, right braces - difference in terms of axial force level.

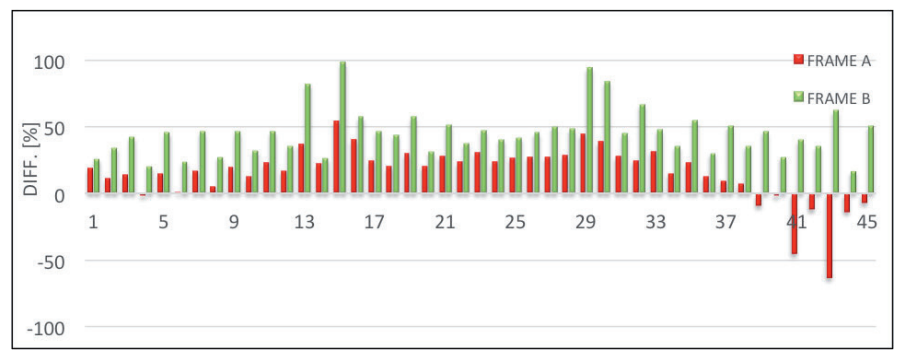

Fig. 21 Frame A vs. Frame B - Difference in axial force (left braces).

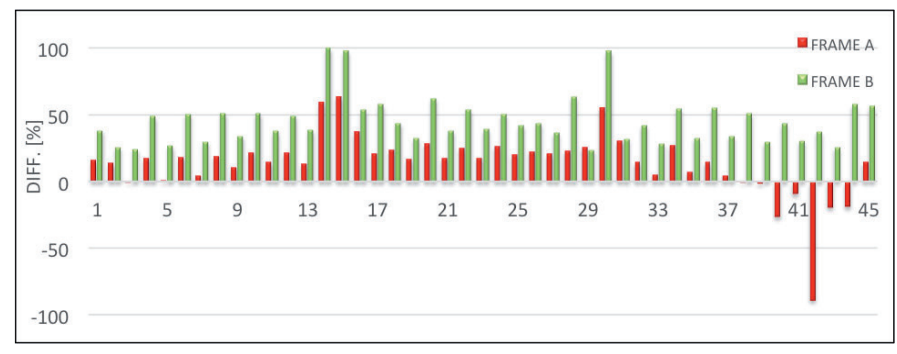

Fig. 22 Frame A vs. Frame B - Difference in axial force (right braces).

It should be also evidenced that left and right braces present similar maxima discrepancies and that the observed mismatch presents similar trends with respect to the total building height. Accordingly, only the numerical results recorded for the most critical right brace of both mega-braced frame-core structures were presented hereafter.

In light of the aforementioned considerations, a measure of the dynamic amplification observed in these vital elements was provided. In detail, Fig. 23 provides a comparison between the compressive peak loads obtained under seismic excitation and static condition in the most critical right brace of the 45 -story building, showing for such structural members dynamic effects much more pronounced than those determined in the columns. An analogous consideration can be also drawn for the 75-story frame-core structure under investigation, as shown in Fig. 24.

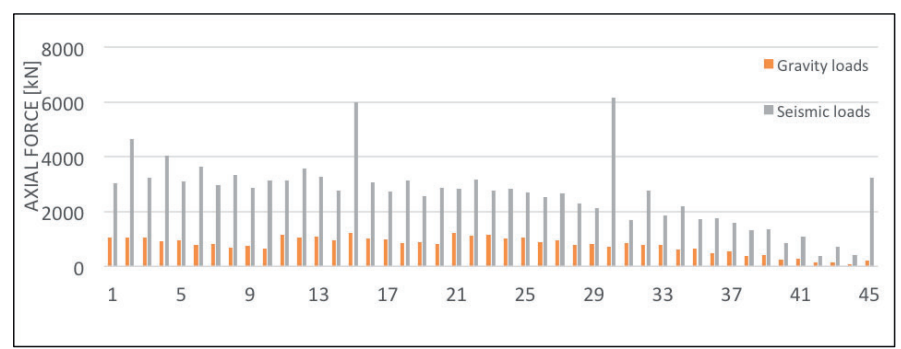

Fig. 23 Static and seismic axial loads - Frame A, right braces. 


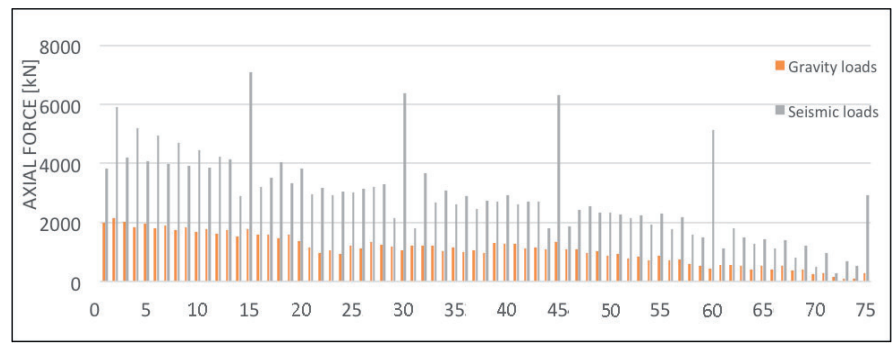

Fig. 24 Static and seismic axial loads - Frame B, right braces.

Given the high dynamic amplification observed and the low accuracy of the most commonly used analysis method for daily office use, the choice of an optimum design target is thus vital to ensure properly balanced response of bracing members and connection systems under seismic loading. This consideration is explicitly recognized in EC8 provisions [30] which prescribe the use of safety factors and material overstrength coefficients to amplify the plastic resistance of dissipative members. More in detail, the axial load obtained from RSA should be increased according to Eq. (2). Hence, the amplified axial load was obtained as shown below:

$$
N_{E d}=1.1 \times y_{o v} \times N_{E d, E}
$$

Where $\mathrm{N}_{\mathrm{Ed}, \mathrm{E}}$ is the value of the axial force experienced under earthquake excitation, while $y_{\mathrm{ov}}$ is an extra-strength coefficient whose value was assumed to be equal to 1.25 as recommended by the European rules [30] regardless of the type of steel used.

As such, the results determined through this approach were compared to the axial force profile obtained from the average of NLTHAs. In this regard, Figs. 25 and 26 show a comparison between them and the amplified axial forces obtained for the right braces of prototypes $\mathrm{A}$ and $\mathrm{B}$, respectively. As previously mentioned, the results obtained for the most critical left braces of both structures presented analogous trends and hence they were not shown.

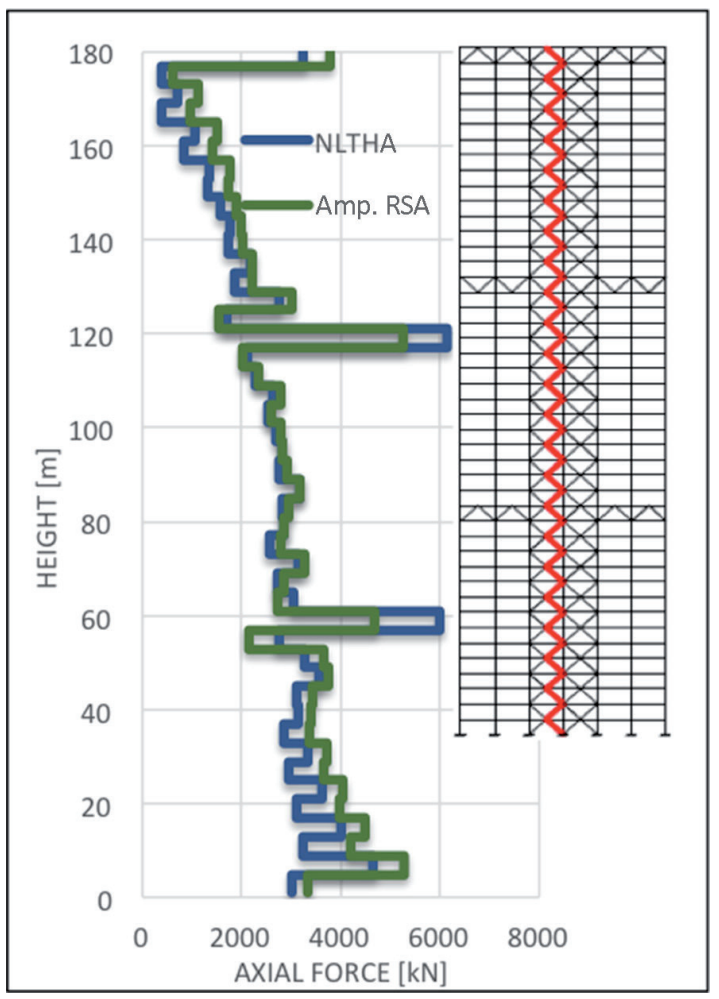

Fig. 25 Amplified axial force - Frame A, right braces.

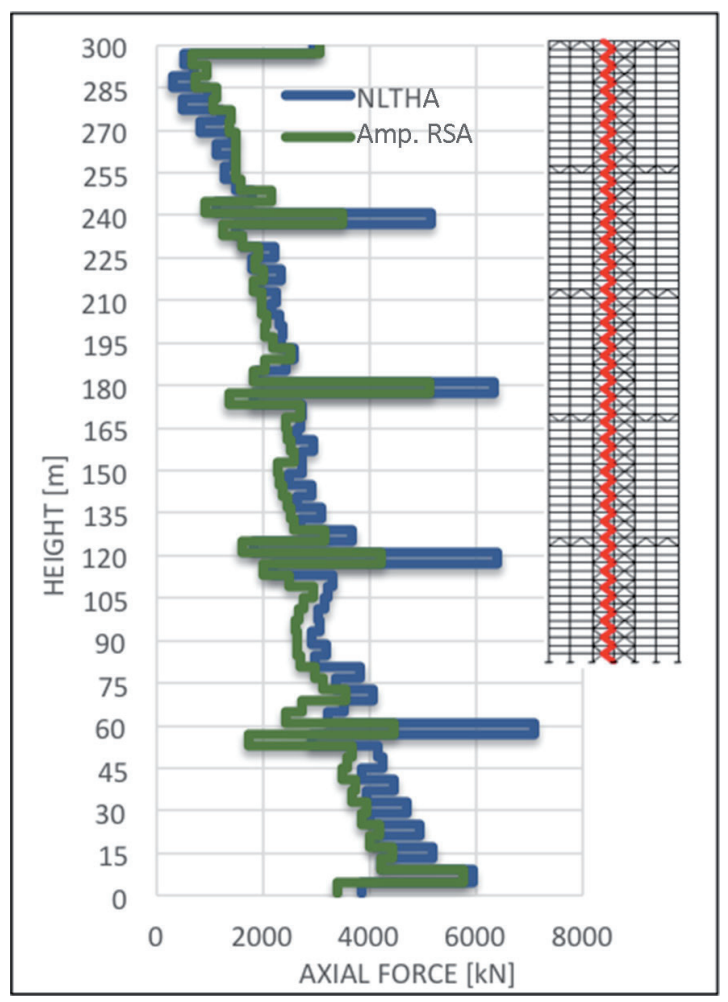

Fig. 26 Amplified axial force - Frame B, right braces. 
Such a code-compliant approach was intended to guarantee the application of hierarchy of strength principles for design of the braces due to the increase of design forces. Despite this, the profiles obtained from the two approaches (i.e. amplified RSA and average of NLTHAs) still revealed a visible discrepancy, especially in correspondence to the outriggers. More in detail, this code-compliant procedure was shown to be unconservative for design purposes. The differences between the two types of approaches remain significant for both case study structures. In detail, they were much more evident for Frame B. Considering that the discrepancy between RSA and NLTHAs was roughly equal to $64 \%$ for Frame A, a mismatch of approximately $20 \%$ was found in this case by applying European seismic rules. In case of Frame B, the difference between RSA and the average of NLTHAs was equal to $100 \%$ and hence the amplification of RSA according to code prescriptions [30] led to a discrepancy of about $70 \%$.

In conclusion, it is worth noting that such a code-compliant RSA-based procedure was proven to be unsafe with respect to the average of NLTHAs. The difference between NLTHAs and RSA remain significant, although the magnitude was shown to decrease when the hierarchy of strength criterion was applied.

\section{Conclusions}

The work described in this paper is chiefly concerned with numerical modeling and multilevel seismic analysis of supertall mega-braced frame-core steel buildings. A 45-story and a 75 -story planar structure with hybrid dual system composed of braces, outriggers, and belts were designed in accordance with current European seismic provisions. A fiber-based mechanical idealization able to reproduce the contribution of connection systems and brace members, accounting for all potential modes of failure, was proposed for seismic response assessment using nonlinear dynamic analysis. The series of analysis results were then compared to response spectrum analysis, thus quantifying the unsafety of the latter if used to predict dynamic effects and multimode response.

The set of analyses and comparisons carried out allows one concluding that a pseudoelastic response controlled by strength rather than ductility was observed for the two high-rise planar structures examined herein, showing both bracing systems and outriggers to be effective in limiting drifts and/or second order effects. On the other hand, these systems were demonstrated to induce high floor accelerations which in turn could adversely impact non-structural components of the building, equipments, furnishings and other assets, as well as the safety of occupants. The bracing system, consisting of a concentrically braced core connected to one-story high belt trusses, was proven to absorb more than $80 \%$ of the seismic-induced action. The presence of the outriggers affected significantly the lateral columns of both structures, making them absorb part of the overturning moment induced by the earthquake excitation in the form of axial load.
Higher mode effects were significant and resulted in a visible discrepancy between RSA and NLTHAs. In detail, the former was unable to predict plastic hinge mechanisms in accurate or at least conservative manner. Code-compliant procedures used to impose the hierarchy of strength principles for the design of connections and key elements were tried, revealing however that the mismatch between them and NLTHAs was still large. Those comparisons demonstrated that RSA-based method was particularly unconservative in correspondence to the outriggers and that the level of unsafety tended to increase as the structure height increased. Finally, a set of IDAs was performed in order to confirm a moderate energy dissipation for the two prototype structures, whose pseudoelastic response was consistent with the design target assumed for $\mathrm{V}$ braces.

\section{References}

[1] Li, C., Lam, S., Zhang, M., Wong, Y. "Shaking table test of a 1:20 scale high-rise building with a transfer plate system." Journal of Structural Engineering. 132(11), pp. 1732-1744. 2006. DOI: 10.1061/(ASCE)0733-9445(2006)132:11(1732)

[2] Lu, X., Zou, Y., Lu, X., Zhao, B. "Shaking table model test on Shanghai world financial center tower." Earthquake Engineering \& Structural Dynamics. 36(4), pp. 439-457. 2007. DOI: 10.1002/eqe.634

[3] Fan, H., Li, Q. S., Tuan, A.Y., Xu, L. "Seismic analysis of the world's tallest building." Journal of Constructional Steel Research. 65(5), pp. 1206-1215. 2009. DOI: 10.1016/j.jcsr.2008.10.005

[4] Lu, X., Lu, X., Guan, H., Zhang, W., Ye, L. "Earthquake-induced collapse simulation of a super-tall mega-braced frame-core tube building." Journal of Constructional Steel Research. 82, pp. 59-71. 2013. DOI: 10.1016/j.jcsr.2012.12.004

[5] Lu, X., Lu, X., Sezen, H., Ye, L. "Development of a simplified model and seismic energy dissipation in a super-tall building." Engineering Structures. 67, pp. 109-122. 2014. DOI: 10.1016/j.engstruct.2014.02.017

[6] Brunesi, E., Nascimbene, R., Rassati, G. , Casagrande, L. "Seismic performance of high-rise steel MRFs with outrigger and belt trusses through nonlinear dynamic FE simulations." In: COMPDYN 2015 - 5th ECCOMAS Thematic Conference on Computational Methods in Structural Dynamics and Earthquake Engineering. Crete Island, Greece, May 25-27, 2015. pp. 721-735.

[7] Brunesi, E., Nascimbene, R., Casagrande, L. "Seismic analysis of highrise mega-braced frame-core buildings." Engineering Structures. 115, pp. 1-17. 2016. DOI: 10.1016/j.engstruct.2016.02.019

[8] Brunesi, E., Nascimbene, R., Rassati, G. A. "Seismic response of highrise mega-braced frame-core buildings through FE analysis." In: Geotechnical and Structural Engineering Congress 2016, Phoenix, Arizona, Feb. 14-17. 2016. pp. 276-287. DOI: 10.1061/9780784479742.023

[9] ANSI/AISC 341-10. "Seismic Provisions for structural steel buildings." Chicago (IL): American Institute of Steel Construction; 2010.

[10] ASCE 7-05. "Minimum design loads for buildings and others structures." Reston (VA): American Society of Civil Engineers; 2006.

[11] SAP2000. "Linear and nonlinear static and dynamic analysis and design of three-dimensional structures." Berkeley (CA), Computers and Structures Inc. (CSI). 2006.

[12] OpenSees (The Open system for earthquake engineering simulation). Berkeley, CA. Pacific Earthquake Engineering Research Center, University of California. 
[13] Nascimbene, R., Rassati, G. A., Wijesundara, K. K. "Numerical simulation of gusset-plate connections with rectangular hollow section shape brace under quasi-static cyclic loading." Journal of Constructional Steel Research. 70, pp. 177-189. 2012. DOI: 10.1016/j.jcsr.2011.09.010

[14] Brunesi, E., Nascimbene, R., Rassati, G. A. "Response of partially-restrained bolted beam-to-column connections under cyclic loads." Journal of Constructional Steel Research. 97, pp. 24-38. 2014.

DOI: 10.1016/j.jcsr.2014.01.014

[15] Brunesi, E., Nascimbene, R., Pagani, M., Beilic, D. "Seismic performance of storage steel tanks during the May 2012 Emilia, Italy, Earthquakes." Journal of Performance of Constructed Facilities. 29(5), 04014137. 2015. DOI: 10.1061/(ASCE)CF.1943-5509.0000628

[16] Brunesi, E., Nascimbene, R., Deyanova, M., Pagani, C., Zambelli, S. "Numerical simulation of hollow steel profiles for lightweight concrete sandwich panels." Computers and Concrete. 15(6), pp. 951-972. 2015. DOI: 10.12989/cac.2015.15.6.951

[17] Brunesi, E., Nascimbene, R. "Numerical web-shear strength assessment of precast prestressed hollow core slab units." Engineering Structures. 102, pp. 13-30. 2015. DOI: 10.1016/j.engstruct.2015.08.013

[18] Bruggi, M. "Generating strut-and-tie patterns for reinforced concrete structures using topology optimization." Computers and Structures. 87(23-24), pp. 1483-1495. 2009. DOI: 10.1016/j.compstruc.2009.06.003

[19] Bruggi, M., Venini, P. "Modeling cohesive crack growth via a truly-mixed formulation." Computer Methods in Applied Mechanics and Engineering. 198(47-48), pp. 3836-3851. 2009. DOI: 10.1016/j.cma.2009.08.018

[20] Bruggi, M., Duysinx, P. "Topology optimization for minimum weight with compliance and stress constraints." Structural and Multidisciplinary Optimization. 46(3), pp. 369-384. 2012.

DOI: $10.1007 / \mathrm{s} 00158-012-0759-7$

[21] Bruggi, M., Taliercio, A. "Topology optimization of the fiber-reinforcement retrofitting existing structures." International Journal of Solids and Structures. 50(1), pp. 121-136. 2013. DOI: 10.1016/j.ijsolstr.2012.09.009

[22] Rassati, G. A., Leon, R. T., Noè, S. "Component modeling of partially restrained composite joints under cyclic and dynamic loading." Journal of Structural Engineering. 130(2), pp. 343-351. 2004. DOI: 10.1061/(ASCE)0733-9445(2004)130:2(343)

[23] Braconi, A., Salvatore, W., Tremblay, R., Bursi, O. S. "Behaviour and modelling of partial-strength beam-to-column composite joints for seismic applications." Earthquake Engineering \& Structural Dynamics. 36(1), pp. 142-161. 2007. DOI: 10.1002/eqe.629

[24] Uriz, P., Filippou, F. C., Mahin, S. A. "Model for cyclic inelastic buckling of steel braces." Journal of Structural Engineering. 134(4), pp. 619628. 2008. DOI: 10.1061/(ASCE)0733-9445(2008)134:4(619)

[25] Wijesundara, K. K., Bolognini D., Nascimbene, R., Calvi, G. M. "Review of design parameters of concentrically braced frames with RHS shape braces." Journal of Earthquake Engineering. 13(S1), pp. 1-23. 2009. DOI: 10.1080/13632460902813331

[26] Wijesundara, K. K., Nascimbene, R., Rassati, G. A. "Modeling of different bracing configurations in multi-storey concentrically braced frames using a fiber-beam based approach." Journal of Constructional Steel Research. 101, pp. 426-436. 2014. DOI: 10.1016/j.jcsr.2014.06.009

[27] Brunesi, E., Nascimbene, R., Rassati, G. A. "Seismic response of MRFs with partially-restrained bolted beam-to-column connections through FE analyses." Journal of Constructional Steel Research. 107, pp. 37-49. 2015. DOI: 10.1016/j.jcsr.2014.12.022
[28] Taranath, B. S. "Structural analysis and design of tall buildings." CRC Press, Taylor \& Francis Group, Boca Raton (FL); 1988.

[29] Gunel, M. H., Ilgin, H. E. "A proposal for the classification of structural systems of tall buildings." Building and Environment. 42(7), pp. $2667-$ 2675. 2007. DOI: 10.1016/j.buildenv.2006.07.007

[30] EN 1998-1-1. "Design of structures for earthquake resistance - Part 1: General rules, seismic actions and rules for buildings." Brussels (Belgium): CEN, European Committee for Standardization; 2005.

[31] Milana, G., Olmati, P., Gkoumas, K., Bontempi, F. "Ultimate capacity of diagrid systems for tall buildings in nominal configuration and damaged state." Periodica Polytechnica Civil Engineering. 59(3), pp. 381-391. 2015. DOI: 10.3311/PPci.7795

[32] Petrini, F., Ciampoli, M. "Performance-based wind design of tall buildings." Structure and Infrastructure Engineering. 8(10), pp. 954-966. 2012. DOI: 10.1080/15732479.2011.574815

[33] EN 1993-1-8. "Design of steel structures - Part 1-8: Design of joints." Brussels (Belgium): CEN, European Committee for Standardization; 2005.

[34] EN 1993-1-12. "Design of steel structures - Part 1-12: General - High strength steels." Brussels (Belgium): CEN, European Committee for Standardization; 2005.

[35] Spacone, E., Filippou, F. C., Taucer, F. F. "Fibre beam-column model for non-linear analysis of RC frames: Part I. Formulation." Earthquake Engineering \& Structural Dynamics. 25(7), pp. 711-725. 1996. DOI: 10.1002/(SICI)1096-9845(199607)25:7<711::AID-EQE576>3.0.CO;2-9

[36] Brunesi, E., Nascimbene, R. "Extreme response of reinforced concrete buildings through fiber force-based finite element analysis." Engineering Structures. 69, pp. 206-215. 2014. DOI: 10.1016/j.engstruct.2014.03.020

[37] Brunesi, E., Nascimbene, R., Parisi, F., Augenti, N. "Progressive collapse fragility of reinforced concrete framed structures through incremental dynamic analysis." Engineering Structures. 104, pp. 65-79. 2015. DOI: 10.1016/j.engstruct.2015.09.024

[38] Maley, T. J., Sullivan, T. J., Lago, A., Roldan, R., Calvi, G. M. "Characterising the seismic behaviour of steel MRF structures - Report EUCENTRE 2013/02." IUSS Press, Pavia, Italy, 2013.

[39] Shome, N., Cornell, C. A., Bazzurro, P., Carballo, J. E. "Earthquakes, records, and nonlinear responses." Earthquake Spectra. 14(3), pp. 469500. 1998. DOI: 10.1193/1.1586011

[40] Iervolino, I., Cornell, C. A. "Record selection for nonlinear seismic analysis of structures." Earthquake Spectra. 21(3), pp. 685-713. 2005. DOI: 10.1193/1.1990199

[41] Hancock, J., Bommer, J. J., Stafford, P. J. "Numbers of scaled and matched accelerograms required for inelastic dynamic analyses." Earthquake Engineering \& Structural Dynamics. 37(14), pp. 1585-1607. 2008. DOI: 10.1002 /eqe. 827

[42] Faccioli, E., Paolucci, R., Rey, J. "Displacement spectra for long periods." Earthquake Spectra. 20(2), pp. 347-376. 2004. DOI: 10.1193/1.1707022

[43] Faccioli, E., Villani, M. "Seismic hazard mapping for Italy in terms of broadband displacement response spectra." Earthquake Spectra. 25(3), pp. 515-539. 2009. DOI: 10.1193/1.3159004

[44] Vamvatsikos, D., Cornell, C. A. "Applied incremental dynamic analysis." Earthquake Spectra. 20(2), pp. 523-553. 2004. DOI: 10.1193/1.1737737

[45] UBC (Uniform Building Code). Whittier (CA): International Council of Building Officials, 1991. 